\title{
CHARACTERIZATION OF Be-IMPLANTED GaN ANNEALED AT HIGH TEMPERATURES
}

\author{
C. RONNING*, K.J. LINTHICUM, E.P. CARLSON, P.J. HARTLIEB, D.B. THOMSON, \\ T. GEHRKE, AND R.F. DAVIS \\ North Carolina State University, Department of Materials Science and Engineering, Box 7919, \\ Raleigh, NC, 27695, USA \\ *University of Göttingen, II. Physical Institute, Bunsenstr. 7-9, D-37073 Göttingen, Germany
}

\begin{abstract}
Single crystalline (0001) gallium nitride layers were implanted with beryllium and subsequently annealed within the range of $300-1100{ }^{\circ} \mathrm{C}$ for $10-60$ minutes under a flux of atomic nitrogen obtained using a rf plasma source. The nitrogen flux protected the GaN surface from decomposition in vacuum at high temperatures. SIMS measurements revealed that no long range diffusion of the implanted Be occurred at 900 or $1100{ }^{\circ} \mathrm{C}$. XRD spectra showed defect-related peaks in the as-implanted samples; these peaks disappeared upon annealing at $900{ }^{\circ} \mathrm{C}$ and higher for 10 minutes. Photoluminescence (PL) measurements showed one new line at $3.35 \mathrm{eV}$ which provided strong evidence for the presence of optically active Be acceptors.
\end{abstract}

\section{INTRODUCTION}

Doping of semiconductors by ion implantation offers advantages in comparison to doping during film growth. (i) The concentration as well as the lateral and depth distributions of the dopants are precisely controllable, and (ii) almost all elements can be implanted with sufficiently high purity. However, this process is compromised by the radiation damage which has to be removed via annealing treatments. In the case of gallium nitride $(\mathrm{GaN})$, this essential annealing procedure for dopant activation is very difficult due to the decomposition of the $\mathrm{GaN}$ surface for temperatures above $900{ }^{\circ} \mathrm{C}[1-3]$. Annealing temperatures $\left(\mathrm{T}_{\mathrm{A}}\right)$ of around $1300{ }^{\circ} \mathrm{C}$ for $>5$ minutes are necessary for GaN to fulfil the rule of thumb claiming that implanted semiconductors should be annealed up to $2 / 3$ of the melting point for satisfying electrical activation [3-5].

At this writing, three special annealing procedures for temperatures above $900{ }^{\circ} \mathrm{C}$ have been investigated with limited success: (i) Rapid thermal annealing (RTA). During this process $\mathrm{GaN}$ is heated up to high temperatures and cooled down within a few seconds. Decomposition is a time dependent diffusion process, and in this small time frame significant decomposition of the implanted layer starts only for temperatures over $1150{ }^{\circ} \mathrm{C}$ [6,7]. (ii) $\mathrm{N}_{2}$-overpressure. Annealing under $\mathrm{N}_{2}$-overpressure in the kbar range opposes the surface decomposition, but only a slightly higher temperature limit of $1250{ }^{\circ} \mathrm{C}$ can be realized due to the exponential rise of the $\mathrm{N}$ vapor pressure as a function of temperature [8]. (iii) Polycrystalline AlN cap. An AlN layer, sputter deposited after the implantation, on top of the GaN layer was used to protect decomposition during annealing. Depending on the crystalline quality of the AlN annealing temperatures of $1300{ }^{\circ} \mathrm{C}$ for $30 \mathrm{sec}$. and good results were reached but only for some selected samples [5,9].

In this article we introduce a new annealing technique which allows the annealing of GaN at a temperature of $1100{ }^{\circ} \mathrm{C}$ for at least 1 hour. We have applied this technique to Beryllium implanted $\mathrm{GaN}$, because achievement and control of substantial activation of p-type dopants in $\mathrm{GaN}$ remains a critical issue vis a vis improved performance of devices fabricated in this material. The most commonly used p-type dopant is magnesium $(\mathrm{Mg})$ which substitutes on $\mathrm{Ga}$ sites and has an ionization energy of $\sim 0.25 \mathrm{eV}$. One-to-two orders of magnitude higher atomic concentration of $\mathrm{Mg}$ must be incorporated into $\mathrm{GaN}$ to achieve the desired hole concentration at 
room temperature [10]. This incorporation reduces the hole mobility due to the enhanced carrierimpurity scattering processes [11]. Beryllium $(\mathrm{Be})$ is a more promising candidate for p-type doping given its measured lower ionization energy of $\sim 0.15 \mathrm{eV}[12,13]$.

\section{EXPERIMENTAL}

One-to-two $\mu \mathrm{m}$ thick epitaxial, monocrystalline and undoped $\mathrm{GaN}$ films were grown on on-axis n-type, Si-face $\alpha(6 \mathrm{H})-\mathrm{SiC}(0001)$ substrates at $1000{ }^{\circ} \mathrm{C}$ and 45 Torr using a vertical, coldwall, RF inductively heated MOVPE deposition system [11]. A $0.1 \mu \mathrm{m}$ high-temperature monocrystalline $\left(1100{ }^{\circ} \mathrm{C}\right)$ AlN-buffer layer was deposited prior to the GaN growth. Deposition was performed using triethylaluminum (TEA) and triethylgallium (TEG) in combination with 1.5 SLM of ammonia $\left(\mathrm{NH}_{3}\right)$ and 3 SLM of $\mathrm{H}_{2}$ diluent.

Beryllium was twice implanted at $100 \mathrm{keV}$ and $200 \mathrm{keV}$ to create a broad depth distribution of this element. The dose ratio between the two implantation energies was $2 / 3$ to adjust the maximum impurity concentration of both implantations. TRIM simulations gave a mean ion range of $276 \mathrm{~nm}(\mathrm{FWHM}=175 \mathrm{~nm})$ and $472 \mathrm{~nm}(\mathrm{FWHM}=1060 \mathrm{~nm})$, respectively, for the two energies [14]. The total implantation dose ranged between $10^{13} \mathrm{~cm}^{-2}$ and $2.5 \times 10^{14} \mathrm{~cm}^{-2}$.

All implanted samples were first sequentially annealed in a tube furnace under vacuum at 300, 600 and $900{ }^{\circ} \mathrm{C}$ for 10 minutes. The samples were transferred into a MBE chamber for annealing at higher temperatures. Heating of the samples was performed under a flux of atomic nitrogen obtained using a rf plasma source (300 W, Model RF 4.5, SVT Associates). The atomic nitrogen flux protected the $\mathrm{GaN}$ surface at $1100{ }^{\circ} \mathrm{C}$ for at least 1 hour using a distance between sample and rf source of around $40 \mathrm{~cm}$.

Secondary ion mass spectroscopy (SIMS) was performed by the Analytical Instrumentation Facility at NC State University using a Cameca IMS-6f. Samples were analyzed with a $200 \mathrm{nA}, 10 \mathrm{keV} \mathrm{O}^{-}$primary beam. Two dimensional $\omega$ - $2 \theta$ X-ray diffraction (XRD) pattern were measured using a Philips $X^{\prime}$ Pert-MRD system with a resolution of $0.001^{\circ}$. Photoluminescence measurements (PL) were performed after each annealing step at $14 \mathrm{~K}$ by exciting the GaN samples with a He-Cd laser $(3.81 \mathrm{eV})$. Hall measurements were done after the deposition of $\mathrm{Ni}(50 \mathrm{~nm})-\mathrm{Au}(100 \mathrm{~nm})$ contacts.

\section{RESULTS AND DISCUSSION}

Figure 1 shows SIMS-profiles of implanted Be with a dose of $10^{13} \mathrm{~cm}^{-2}$ before and after annealing at $900{ }^{\circ} \mathrm{C}$ and $1100{ }^{\circ} \mathrm{C}$ for 15 minutes. Both implantation profiles of the $100 \mathrm{keV}$ and $200 \mathrm{keV}$ implantation are clearly visible and in good agreement with TRIM calculations [14]. Within the experimental resolution, no long range diffusion was observed after annealing. This observation is in agreement with Ref. [15], where also no redistribution was observed up to $800{ }^{\circ} \mathrm{C}$. This excellent thermal stability of $\mathrm{Be}$ in $\mathrm{GaN}$ indicates a strong bonding of $\mathrm{Be}$ in the lattice. Therefore, diffusion of $\mathrm{Be}$ into $\mathrm{GaN}$ from an external source is not practical and ion

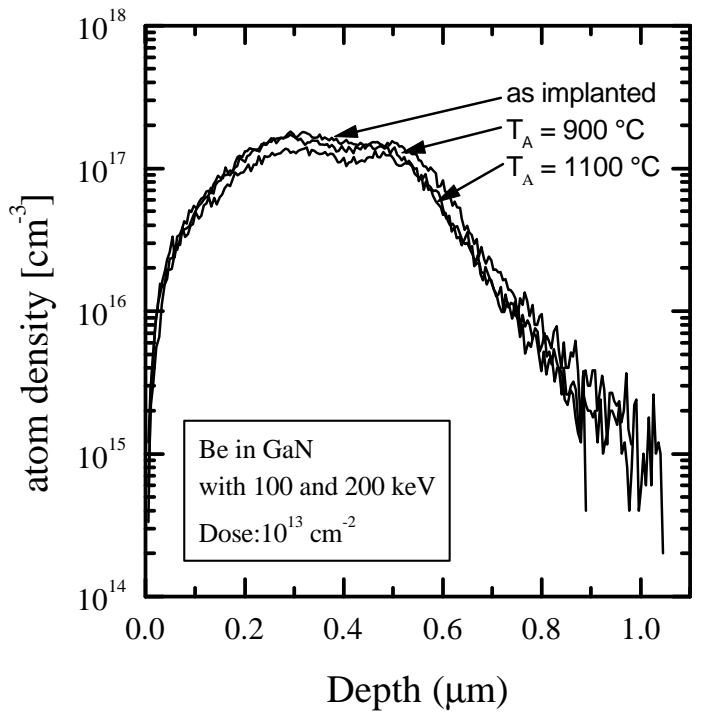

Figure 1: SIMS profiles of Be implanted in $\mathrm{GaN}$, unannealed and annealed to $900{ }^{\circ} \mathrm{C}$ and $1100{ }^{\circ} \mathrm{C}$ for 15 minutes. 

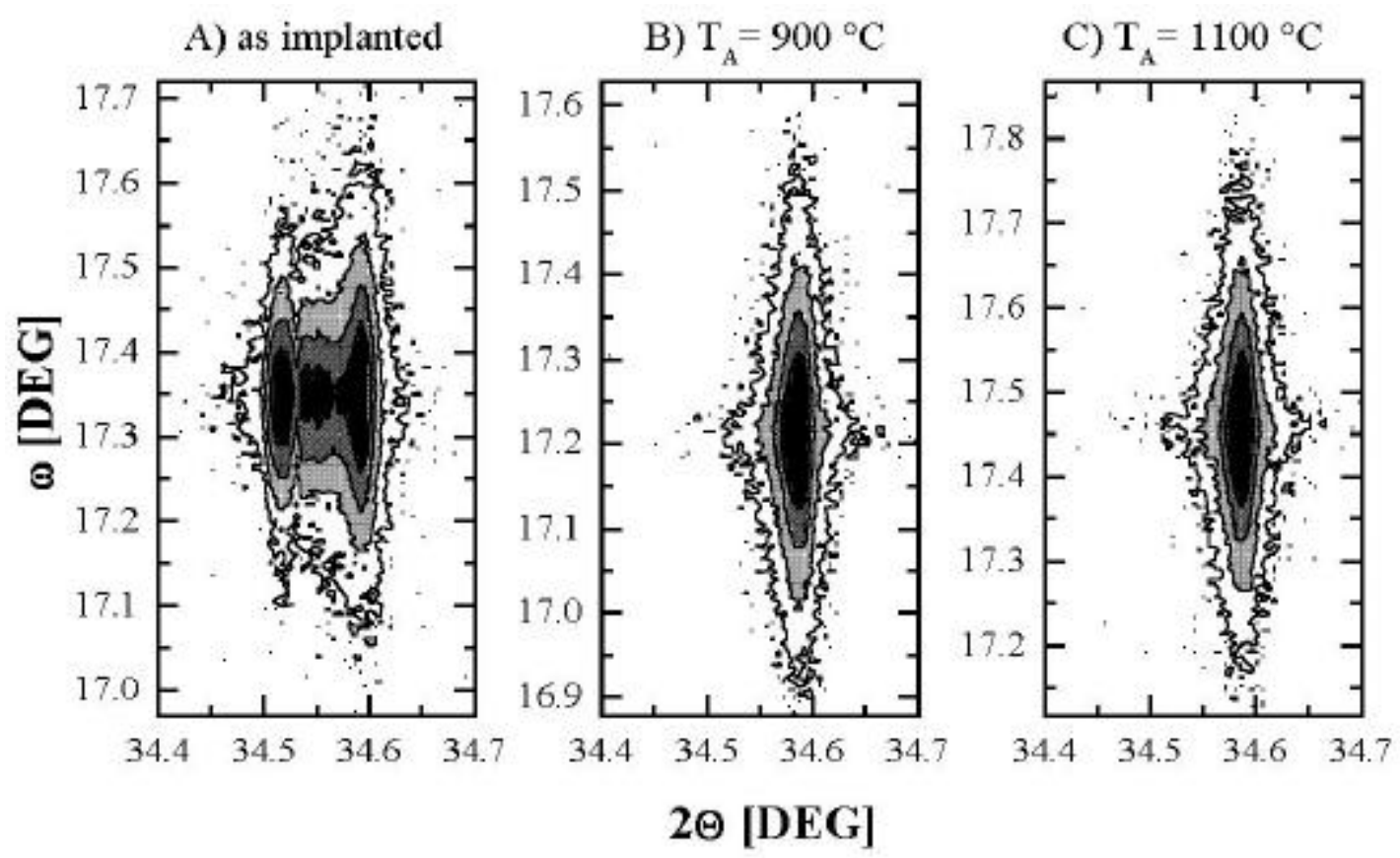

Figure 2: XRD 2-axis $\omega$-2 $\theta$ map of the (0002) GaN peak (A) dirctly after Be implantation with a dose of $2.5 \times 10^{14} \mathrm{~cm}^{-2}$ and after subsequent annealing to a temperature of $900{ }^{\circ} \mathrm{C}(\mathrm{B})$ and $1100{ }^{\circ} \mathrm{C}(\mathrm{C})$ for 10 minutes. (Note: contour plots have log-scale).

implantation or epitaxial growth are the only possibilities to introduce Be into GaN.

Figure 2A displays a two dimensional $\omega$-2 $\theta$ X-ray diffraction (XRD) pattern of the GaN (0002) peak of a Be-implanted sample with a dose of $2.5 \times 10^{14} \mathrm{~cm}^{-2}$. Note: A vertical section of figure 2 is a rocking curve. No significant broadening of the rocking curve was observed compared to the non-implanted situation, but one remarkable characteristic is that a few new peaks appeared at the left side of the (0002) peak after the implantation process. The intensity of these peaks increased at the expense of the main (0002) peak with growing implantation dose. This effect has already been observed [16] and can easily be attributed to an expansion of the $\mathrm{GaN}$ crystal lattice by interstitials created during the implantation process. This strong defect related peaks disappeared already upon annealing at $900{ }^{\circ} \mathrm{C}$ for 10 minutes (Figure 2B) resulting into a spectrum which is comparable to the non-implanted spectrum. Consequently, no improvement was observed for a higher annealing temperature of $1100{ }^{\circ} \mathrm{C}$ (Figure $2 \mathrm{C}$ ). We can conclude that in the view of XRD the GaN lattice is already fully recovered after annealing at a temperature of $900{ }^{\circ} \mathrm{C}$.

The low temperature PL spectra of a Be-implanted GaN sample with a dose of $5 \times 10^{13} \mathrm{~cm}^{-2}$ are summarized in Fig. 3. No PL lines were observed directly after ion implantation for this dose, but they were observed in the case of lower implantation doses. After annealing to a temperature of $900{ }^{\circ} \mathrm{C}$ for 15 minutes PL lines have been detected. However, the intensity of the band edge luminescence is several orders of magnitude lower in comparison to as-grown, unimplanted GaN samples. The weak luminescence line at $3.467 \mathrm{eV}$ (commonly labeled as $\mathrm{I}_{2}$ ) in Fig. 3 originates from recombinations of free excitons and/or excitons bound to shallow donors. The LO-phonon replicas for this line could not be observed in the implanted samples due to its low intensity; however, their positions at $3.384 \mathrm{eV}$ and $3.292 \mathrm{eV}$ were determined from the asgrown, unimplanted $\mathrm{GaN}$ grown on the same $\mathrm{SiC}$-wafer. This results in a phonon energy of about $85 \pm 5 \mathrm{meV}$ for our samples, which is in agreement with values in the literature [17]. The second 
luminescence peak at $3.444 \mathrm{eV}$ is most likely related to defects created during the implantation procedure, as this line also was observed with varying intensities after implantation of $\mathrm{Li}, \mathrm{Si}, \mathrm{Ge}$, In and Er [18]. We believe that this line is produced by nitrogen vacancies due to donor-band (eD) transitions, because it appears also in unimplanted GaN samples depending on the growth conditions.

One Be related transition with low intensity was observed at $3.35 \mathrm{eV}$. The intensity of this line varied as a function of the lateral quality of the $\mathrm{GaN}$ sample. We attribute this line to bandacceptor (eA) recombinations. For this case, the ionization energy of Be acceptors was calculated to be $150 \pm 10 \mathrm{meV}$ [12]. Dewsnip and co-workers [13] also observed a new line in GaN samples doped with Be during growth at $3.376 \mathrm{eV}$. However, they calculated the ionization energy to be $90-100 \mathrm{meV}$ due to the assumption that this line is a donor-to-acceptor transition. Temperature dependent PL measurements showed different intensity behaviors of the lines at $3.444 \mathrm{eV}$ and $3.35 \mathrm{eV}$; therefore, we can exclude that the line at $3.35 \mathrm{eV}$ is a phonon replica of the $3.444 \mathrm{eV}$ line. Furthermore, we never observed the line at 3.35 $\mathrm{eV}$ after implantation of $\mathrm{Li}, \mathrm{Si}, \mathrm{Ge}$, In and $\mathrm{Er}$ into $\mathrm{GaN}$ even when the line at $3.444 \mathrm{eV}$ was present [18]. These observations prove that the line at 3.35 $\mathrm{eV}$ is only related to the implanted Be acceptors.

Figure 3 also shows the recorded PL spectra for the same Be implanted GaN sample as a function of annealing temperature. Conflicting with the XRD-results, the implanted material was only partly recovered in view of PL at an annealing temperature of $900{ }^{\circ} \mathrm{C}$, which is in agreement with Ref. [19]. After annealing to $1100{ }^{\circ} \mathrm{C}$ for 15 minutes a strong recovery of the PL lines occurred and was further improved after the 1 hour anneal. The intensity of the $\mathrm{I}_{2}$-line grew more than two orders of magnitude and reached about $80 \%$ of the intensity of the pre-implanted samples. However, the defect-related line at $3.444 \mathrm{eV}$ is still visible and the Be-related line did not grow after the $1100{ }^{\circ} \mathrm{C}, 1$ hour anneal. We can conclude that in view of the PL the implanted GaN is almost recovered after the $1100{ }^{\circ} \mathrm{C}, 1$ hour annealing step, but point defects (invisible to XRD) are still present and may create Be-defect complexes, which are responsible for the low optical activation of Be acceptors. 


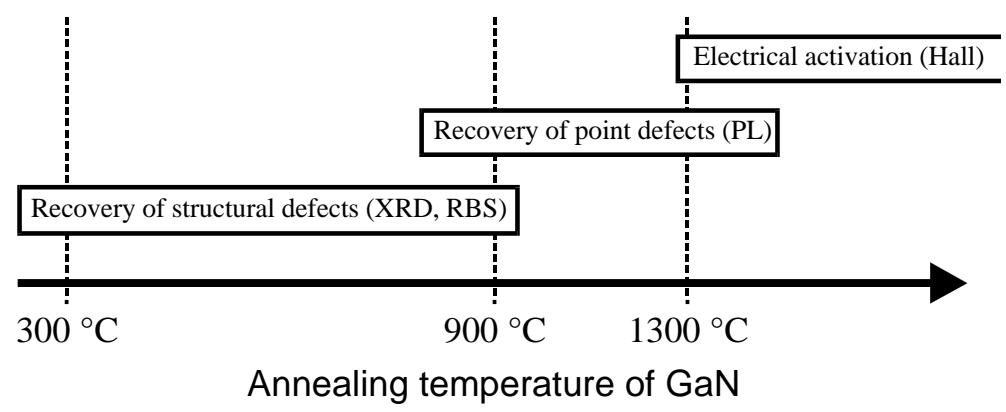

Figure 4: Fundamental recovery processes in ion implanted $\mathrm{GaN}$ and their detection methods as a function of annealing temperature (15 minutes).

Hall effect measurements were carried out after annealing to $1100{ }^{\circ} \mathrm{C} \quad(1$ hour $)$ and deposition of $\mathrm{Ni}-\mathrm{Au}$ contacts. All

samples were too resistive for the determination of carrier concentrations or mobilities due to the remaining defects, which are creating compensating deep levels in the band gap.

\section{CONCLUSIONS}

We have summarized in Figure 4 the fundamental recovery processes in ion implanted $\mathrm{GaN}$ as a function of annealing temperature. The crystal structure of $\mathrm{GaN}$ is very resistant to ion bombardment due to the high ionicity of the Ga-N bond. This results in very high doses for amorphization [16]. However, structural defects can be readily created with medium implantation doses $\left(10^{14}-10^{15} \mathrm{~cm}^{-2}\right)$, which can be detected by XRD or RBS-channeling [20]. These defects (mainly interstitials) lead to a lattice expansion which can be removed/recombined upon annealing to $900{ }^{\circ} \mathrm{C}$. The recovery of point defects, visible by PL, starts around $800{ }^{\circ} \mathrm{C}$ and is not completed at a temperature of $1100{ }^{\circ} \mathrm{C}$. Around $80 \%$ of the free exciton line is recovered at this point. Based on primary observations on Mg-implanted $\mathrm{GaN}$ [21], we predict that after annealing to $1300{ }^{\circ} \mathrm{C}$ the $\mathrm{GaN}$ crystal is completely recovered and macroscopic electrical activation of the implanted impurities takes place.

We introduced in this article a new annealing procedure under a flux of atomic nitrogen obtained using a rf plasma source. In contrast to the $\mathrm{N}_{2}$-overpressure technique [8] where the loss of nitrogen is prevented by the hydrostatic pressure, the atomic nitrogen flux protects the $\mathrm{GaN}$ surface by an exchange of nitrogen between solid and gas phase. An increase of the flux density by reducing the distance or increasing the power should result in the possibility to anneal GaN even to higher temperature as $1100^{\circ} \mathrm{C}$.

\section{ACKNOWLEDGMENTS}

The authors would like to thank D.P. Griffis and G.M. Guryanov for doing the SIMS measurements and Cree Research, Inc. for supplying the $\mathrm{SiC}$ substrates for this research. The implantations were conducted by ImplantSciences, Wakefield, MA (USA). This work was supported by the ONR under Contract N00014-92-J-1477 (M. Yoder, technical monitor). C.R. is grateful for funding by the DFG (Ro 1198/2-1). R. Davis was supported in part by the Kobe Steel, Ltd. Professorship.

\section{REFERENCES}

1. S.W. King, J.P. Barnak, M.D. Bremser, K.M. Tracy, C. Ronning, R.F. Davis, R.J. Nemanich, J. Appl. Phys. 84, 5248 (1998).

2. C.B. Vartuli, S.J. Pearton, C.R. Abernathy, J.D. MacKenzie, E.S. Lambers, J.C. Zolper, J. Vac. Sci. \& Techn. B 14, 3523 (1996). 
3. O. Ambacher, J. Phys. D: Appl. Phys. 31, 2653 (1998).

4. J.H. Edgar (ed.), Group III Nitrides, London, INSPEC (1994).

5. J.C. Zolper, S.J. Pearton, J.S. Williams, H.H. Tan, R.J. Karlicek, R.A. Stall, Mater. Res. Soc. Proc. Vol. 449, 981 (1997).

6. H.H. Tan, J.S. Williams, J. Zou, D.J.H. Cockayne, S.J. Pearton, J.C. Zolper, R.A. Stall, Appl. Phys. Lett. 72, 1190 (1998).

7. S. Strite, P.W. Epperlein, A. Dommann, A. Rockett, R.F. Broom, Mater. Res. Soc. Proc. Vol. 395, 795 (1996).

8. S. Strite, A. Pelzmann, T. Suski, M. Leszczynski, J. Jun, A. Rockett, M. Kamp , K. J. Ebeling, MRS Internet J. Nitride Semicond. Res. 2, 15 (1997).

9. J.C. Zolper, J. Han, R.M. Biefeld, S.B. van Deusen, W.R. Wampler, S.J. Pearton, J.S. Williams, H.H. Tan, R.J. Karlicek, R.A. Stall, Mater. Res. Soc. Proc. Vol. 468, ? (1997).

10. U. Kaufmann, M. Kunzer, M. Maier, H. Obloh, A. Ramakrishnan, B. Santic, P. Schlotter, Appl. Phys. 72, 1326 (1998).

11. T.W. Weeks, Jr., M.D. Bremser, K.S. Ailey, E.P. Carlson, W.G. Perry, R.F. Davis, Appl. Phys. Lett. 67, 401 (1995); J. Mat. Res. 11, 1011(1996).

12. C. Ronning, E.P. Carlson, D.B. Thomson, R.F. Davis, Appl. Phys. Lett. 73, 1622 (1998).

13. D.J. Dewsnip, A.V. Andrianov, I. Harrison, J.W. Orton, D.E. Lacklison, G.B. Ren, S.E. Hooper, T.S. Cheng, C.T. Foxon, Semicond. Sci. Technol. 13, 500 (1998).

14. J.F. Ziegler, J.P. Biersack, and U. Littmark, The stopping and ranges of ions in solids, (Pergamon Press, New York, 1985).

15. R.G. Wilson, S.J. Pearton, C.R. Abernathy, and J.M. Zavada, Appl. Phys. Lett. 66, 2238 (1995).

16. C. Liu, B. Mensching, K. Volz, B. Rauschenbach, Appl. Phys. Lett. 71, 2313 (1997).

17. S. Fischer, C. Wetzel, E.E. Haller, B.K. Meyer, Appl. Phys. Lett. 67, 1298 (1995).

18. E.P. Carlson, C. Ronning, R.F. Davis, unpublished.

19. C. Ronning, M. Dalmer, M. Deicher, M. Restle, H. Hofsäss, M.D. Bremser, R.F. Davis, Mat. Res. Soc. Proc. Vol. 468, 407 (1997), and Ref. therein.

20. N. Parikh, A. Suvkhanov, M. Lioubtchenko, E.P. Carlson, M.D. Bremser, D. Bray, R.F. Davis, J. Hunn, Nucl. Instr. Meth. B 127/128, 463 (1997).

21. C. Ronning, A. Stötzler, E.P. Carlson, P. Rajago, R.F. Davis, unpublished. 